\title{
FDA Perspectives on the Use of Teratology Data for Human Risk Assessment ${ }^{1}$
}

\author{
VASILIOS H. FRANKOS ${ }^{2}$ \\ Food and Drug Administration
}

\begin{abstract}
FDA Perspectives on the Use of Teratology Data for Human Risk Assessment. FRANKos, V. H. (1985). Fundam. Appl. Toxicol. 5, 615-625. 1985 Society of Toxicology.
\end{abstract}

Looking back to the tragedy of thalidomide leaves us with a sense of relief that no other teratogens as devastating as thalidomide have reached the market. Certainly as toxicologists, we have learned much from this unfortunate experience. Previous to this horror, little animal teratology testing was routinely required of foods and drugs and usually only if marked sex organ effects were observed (Fitzhugh, 1959). The public and the scientific community were generally unaware of the potential of chemical agents to cause human malformations and thus remained complacent. The lesson of thalidomide lies in how it shook the public and the scientific community from its complacent sleep and made it painfully aware of the "potential" harm chemicals can cause to our unborn children. For toxicologist, the myth that teratology only occurs after maternal toxicity was shattered.

This rude awakening prompted quick action by Congress on badly needed reform of the drug laws (1962 Kefauver-Harris Amendments of the 1938 Food, Drug, and Cosmetic Act). This act required performance of certain animal studies prior to clinical testing of a drug and more extensive clinical studies before a drug could be approved for

\footnotetext{
' Presented at the 23rd Annual Conference of the Society of Toxicology, March 12-16, 1984, Atlanta, Ga., as part of a symposium entitled Risk Assessment for Developmental Toxicity.

2 Present address: Environ Corp., The Flour Mill, 1000 Potomac St., N.W. Washington, D.C. 20007.
}

marketing. Interest also intensified in establishing guidelines for animal testing of potential teratogenic or reproductive hazards associated with exposure to chemical agents. These changes were followed by specific guidelines for the now familiar FDA three-segment reproduction study of drugs (USFDA, 1966; Kelsey, 1974). These guidelines required preclinical animal testing for each new drug depending on how women might be exposed to the drug. Segment I addresses fertility and general reproductive performance, Segment II requires classic teratology animal testing, and Segment III limits treatment to the perinatal and postnatal period. Testing requirements for food additives, color additives, and animal drugs administered to food producing animals were extended to include multigeneration reproduction studies with a teratology phase incorporated into the design. Separate teratology studies in other species were also required depending on the outcome of the reproduction studies (USFDA, 1970; Collins, 1978). Although three-generation studies were required until a few years ago, the current recommended guidelines require as a minimum a two-generation reproduction design with a teratology phase. Additional generations can be instituted if the data produced warrant it. These studies are followed by a teratology study in another species if needed.

This increasing requirement for teratology testing forced regulatory scientists into having to review and evaluate an enormous amount 
of new teratology information without the benefit of previous precedent in using these data for human safety assessment. To confound matters, the relevance of animal teratology studies to human risk assessment was not clearly established when animal reproduction and teratology testing guidelines were established for substances regulated by FDA. Although birth defects in humans still occur at the rate of $3-6 \%$, fortunately no new teratogens with the potency of thalidomide's have been identified even after 20 years of extensive animal reproduction and teratology testing. Unfortunately, even as the list of animal teratogens grows longer and longer, few significant advances have been made to increase our understanding of the mechanism of teratogenesis and our ability to extrapolate these findings to human reproductive hazards assessment. Certainly before attacking the question of how to conduct quantitative and qualitative risk assessments for developmental toxicity, one must clearly establish the relationship between effects in animals and man and define what animal endpoint can be used for human risk assessment.

The importance of scientific support for using animal teratology studies for human risk assessment was made painfully clear when the FDA proposed to delete the GRAS status of caffeine and place it on the interim list (USFDA, 1980). At that time, I was assigned to the Commissioner's office and was asked to critically evaluate the fundamental assumption that human reproductive health risk can be estimated by extrapolating animal developmental toxicity data to humans.

This assumption is the cornerstone of most of FDA's decisions regarding the safety of substances in the food supply. In accepting this assumption, however, FDA does not assume that responses in animal models reflect exactly what will occur qualitatively or quantitatively in humans. What is assumed is the ability of well-designed animal studies to provide an indication of potential risk to humans. Only after careful analysis of exper- imental results from multiple species can a degree of confidence be ascribed to the probability that this potential risk will materialize in the human population. If it can be demonstrated scientifically, however, that a result from a particular animal study is not relevant as a predictor of human risk, then that result would not be employed in making safety assessments no matter how drastic the animal results. Although, ultimately, conclusions regarding the precise risk to humans for any substance can only be arrived at by using appropriate human data, until this occurs, it is prudent to avoid or limit fetal exposure to such agents.

The interpretation of the relevance of teratology studies to humans is affected by many considerations, which combine to make the interpretation of teratology studies complex, difficult, and uncertain (Wilson and Fraser, 1977a; Council on Environmental Quality, 1981; Yerushalmy, 1972). These considerations, which are examined whenever one attempts to extrapolate from an observed teratologic response in one species to what might be expected to occur in another, include the following:

(1) Physiological and biochemical differences that affect the absorption, metabolism, and excretion of the substance.

(2) Variability in placental barriers.

(3) Differences in susceptibility to chemical interactions at the cell, tissue, and organ system levels.

(4) Variability in background incidence of disease.

(5) Variability in the gestational development sequence.

These factors must be taken into account, to the extent the available data permit, when one attempts to assess the relevance to humans of any specific teratology study conducted in a particular species on a particular chemical (Fraser, 1977).

In an effort to better understand as a general matter the relevance of animal teratology studies to humans, several investigators 
have examined the literature to determine the extent to which known or suspected human teratogens have also been found to be teratogenic in animals (Wilson, 1973; Schardein, 1976; Strobino et al., 1978). FDA's review of the literature (Table 1) reveals a group of 38 compounds for which there are reports of birth defects in humans associated with intakes of these compounds during pregnancy (Strobino et al., 1978; Schardein, 1976; Shepard, 1976; U.S. Pharmacopeia, 1980). Of these compounds, all except one have a positive study in at least one animal test species. Furthermore, over $80 \%$ of the compounds are positive in multiple species. The one exception is a compound that causes otological deficits in humans that would not normally be discovered in test animals at the time of cesarean sacrifice.

Among the substances identified as known or suspected human teratogens (Table 2), a positive teratologic response was exhibited $85 \%$ of the time in the mouse, $80 \%$ in the rat, $60 \%$ in the rabbit, $45 \%$ in the hamster, and only $30 \%$ in the monkey. Other species have been used to test only a small number of these substances.

The corrclations between human response and the responses of individual test species are not as good for the compounds that do not appear to be human teratogens (Table 3 ). Of the 165 compounds which specifically have been reported as having no evidence of

TABLE 1

SUMmary OF TERATOLOGY FINDINGS IN ANIMALS AND HUMANS

Positive Teratologic Findings Reported in Humans

Number of compounds studied 38

Positive in at least one other test species Positive in more than one other test species Positive in all other species tested

No Teratologic Findings Reported in Humans Number of compounds studied

Nonpositive in at least one other species Nonpositive in more than one other species Nonpositive in all other species tested
TABLE 2

Outcome of Teratologic Testing IN Multiple SPECIES For SusPected Human TERATOGENS

\begin{tabular}{|c|c|}
\hline Compound & Ratio $^{a}$ \\
\hline Aminopterin & $4 / 7$ \\
\hline Amphetamine & $2 / 3$ \\
\hline Aspirin & $5 / 7$ \\
\hline 6-Azauridine & $3 / 4$ \\
\hline Busulfan & $2 / 3$ \\
\hline Carbutamide & $3 / 3$ \\
\hline Chlorambucil & $3 / 3$ \\
\hline Chlordiazepoxide & $1 / 2$ \\
\hline Chloroquine & $1 / 3$ \\
\hline Chlorpromazine & $2 / 4$ \\
\hline Cyclophosphamide & $3 / 5$ \\
\hline Diazepam & $1 / 5$ \\
\hline Diethylstilbestreol & $2 / 4$ \\
\hline Dihydrostreptomycin & $1 / 2$ \\
\hline Diphenylhydantoin & $3 / 3$ \\
\hline Ethanol & $3 / 6$ \\
\hline Iodine & $4 / 4$ \\
\hline Lithium carbonate & $2 / 4$ \\
\hline LSD & $4 / 5$ \\
\hline Meprobamate & $1 / 3$ \\
\hline Methotrexate & $5 / 5$ \\
\hline Methyltestosterone & $4 / 5$ \\
\hline Methylthiouracil & $3 / 3$ \\
\hline Nitrogen mustard & $3 / 3$ \\
\hline Organic mercury & $1 / 4$ \\
\hline Phenobarbital & $3 / 4$ \\
\hline Progesterone & $3 / 6$ \\
\hline Propylthiouracil & $4 / 4$ \\
\hline Quinine & $2 / 6$ \\
\hline Streptomycin & $2 / 3$ \\
\hline Testosterone & $9 / 10$ \\
\hline Tetracycline & $2 / 4$ \\
\hline Thalidomide & $9 / 10$ \\
\hline Tobramycin & $0 / 3$ \\
\hline Tolbutamide & $3 / 4$ \\
\hline Trimethadione & $1 / 3$ \\
\hline Vitamin A & $8 / 9$ \\
\hline Warfarin sodium & $1 / 2$ \\
\hline
\end{tabular}

${ }^{\infty}$ Ratio of the number of species found positive to the number of species tested.

being human teratogens, $29 \%$ appeared negative in all animal species tested and 50\% appeared negative in multiple species. However, $41 \%$ of these 165 compounds appeared to be positive in more than a single animal species. For the most commonly tested species, a nonpositive response to the substances 
TABLE 3

Outcome of Teratologic Testing in Multiple Species for Compounds with No Positive Reports in HUMANS

\begin{tabular}{|c|c|c|c|c|c|}
\hline Compound & Ratio $^{a}$ & Compound & Ratio $^{a}$ & Compound & Ratio $^{\circ}$ \\
\hline Acetaminophen & $0 / 1$ & Dexamethasone & $4 / 6$ & Methaqualone $\mathrm{e}^{b}$ & $2 / 3$ \\
\hline Acetazolamide & $4 / 5$ & Diacetylmorphine & $1 / 1$ & Methedrine & $2 / 2$ \\
\hline ACTH & $1 / 4$ & Dicyclomine $^{b}$ & $0 / 2$ & Methyl ethyl ketone & $1 / 1$ \\
\hline Actinomycin D & $4 / 4$ & Dieldrin & $2 / 4$ & Methyldopa & $0 / 3$ \\
\hline Aldrin & $2 / 2$ & Diethylpropion & $0 / 2$ & Methylprednisolone & $1 / 3$ \\
\hline Allopurinol & $1 / 3$ & Dimenhydrinate & $0 / 2$ & Minocycline $^{b}$ & $2 / 4$ \\
\hline Allylestrenol & $1 / 1$ & Dimethyl sulfoxide & $3 / 4$ & Mirex & $2 / 2$ \\
\hline Aminophylline & $1 / 2$ & Diphenhydramine & $0 / 3$ & Mitomycin C & $2 / 2$ \\
\hline Amitriptyline & $1 / 3$ & Disulfiram & $0 / 2$ & Morphine & $2 / 3$ \\
\hline Ampicillin & $0 / 2$ & Doxapram & $0 / 2$ & Nalidixin acid & $2 / 3$ \\
\hline Arsenic & $1 / 3$ & Doxepin & $0 / 2$ & Naproxen & $0 / 3$ \\
\hline L-Asparaginase & $2 / 2$ & Doxycycline $^{b}$ & $0 / 4$ & Niacin & $0 / 1$ \\
\hline Azathioprine & $3 / 4$ & Doxylamine & & Nicotine & $1 / 4$ \\
\hline Beclomethasone & $2 / 2$ & succinate & $0 / 2$ & Norethynodrel $^{b}$ & $1 / 3$ \\
\hline Bendazol & $1 / 3$ & Endrin & $2 / 3$ & Oxazepam & $0 / 3$ \\
\hline Benzene & $1 / 2$ & Epinephrine & $3 / 5$ & Oxytetracycline $^{b}$ & $2 / 4$ \\
\hline 3,4-Benzpyrene & $2 / 2$ & Estradiol benzoate $^{b}$ & $1 / 4$ & Penicillin & $1 / 4$ \\
\hline Betamethasone & $2 / 4$ & Ethinyl estradiol $^{b}$ & $0 / 2$ & Pentazocine & $1 / 3$ \\
\hline Butaperazine & $1 / 3$ & Estrone $^{b}$ & $2 / 5$ & Pentobarbital & $1 / 5$ \\
\hline Caffeine & $3 / 3$ & Ethosuximide $^{h}$ & $1 / 1$ & Perphenazine & $2 / 3$ \\
\hline Carbamazepine & $1 / 1$ & Ethionamide & $2 / 3$ & Phenylzine & $1 / 3$ \\
\hline Carbaryl & $2 / 5$ & Fenoprofen & $0 / 2$ & Phenylbutazone & $0 / 2$ \\
\hline Carbenicillin & $0 / 2$ & Fenfluraminc & $0 / 4$ & Pimaricin & $0 / 1$ \\
\hline Carbon tetrachloride & $1 / 3$ & 5-Fluorouracil & $4 / 5$ & Piperacetazine & $0 / 3$ \\
\hline Cefazolin & $0 / 3$ & Fluphenazine ${ }^{b}$ & $1 / 3$ & Primaclone & $1 / 1$ \\
\hline Cephalexin & $0 / 2$ & Glutethimide & $1 / 3$ & Predisolone & $4 / 4$ \\
\hline Cephradine & $0 / 2$ & Grisofulvin & $2 / 2$ & Procarbazine & $3 / 3$ \\
\hline Chloramphenicol & $1 / 4$ & Haloperidol & $2 / 4$ & Probenecid & $0 / 1$ \\
\hline Chlormadione & $3 / 4$ & Halothane & $2 / 5$ & Propoxyphene ${ }^{\delta}$ & $1 / 4$ \\
\hline Chloroform & $2 / 3$ & Heparin & $0 / 2$ & Prochlorperazine & $2 / 3$ \\
\hline Chlortetracycline ${ }^{\triangleright}$ & $0 / 2$ & Hydantoin & $2 / 3$ & Prostaglandin E2 & $2 / 5$ \\
\hline Chlorpropamide $^{\mathrm{b}}$ & $1 / 2$ & Hydrocortisone & $5 / 6$ & Propranolol & $0 / 2$ \\
\hline Clindamycin & $0 / 2$ & Hydroxyurea & $7 / 7$ & Pyrimethamine & $2 / 4$ \\
\hline Clomiphene & $3 / 4$ & Hydroxyzine $^{b}$ & $4 / 4$ & Pteroylglutamic acid & $1 / 4$ \\
\hline Clonidine & $0 / 3$ & Ibuprofen & $0 / 2$ & Rifamide & $2 / 3$ \\
\hline Codeine & $1 / 1$ & Imimramine $^{b}$ & $1 / 4$ & Reserpine & $1 / 4$ \\
\hline Colcemid & $1 / 4$ & Indomethacin & $0 / 3$ & Rifampicin & $2 / 3$ \\
\hline Colchicine & $4 / 5$ & Insulin & $3 / 3$ & Saline & $1 / 3$ \\
\hline Corticosterone & $3 / 3$ & Isocarboxazid & $0 / 3$ & Serotonin & $2 / 3$ \\
\hline Cortisone & $3 / 3$ & Isoniazid & $0 / 3$ & Sodium barbital & $1 / 3$ \\
\hline Coumarin & $0 / 3$ & Isoproterenol & $3 / 4$ & Sodium bicarbonate & $0 / 1$ \\
\hline Curare & $1 / 2$ & Kenamycin & $1 / 4$ & Sodium chloride & $1 / 6$ \\
\hline Cyclizine & $3 / 3$ & Lincomycin & $0 / 3$ & Sodium salicylate & $3 / 4$ \\
\hline Cyclofenil & $0 / 2$ & Meclizine $^{b}$ & $1 / 5$ & Streptonigrin & $1 / 2$ \\
\hline Cycloserine & $0 / 1$ & Medroxyprogesterone & & Sulfadiazine & $0 / 3$ \\
\hline Cysteine & $0 / 1$ & acetate ${ }^{b}$ & $2 / 4$ & TEM & $2 / 4$ \\
\hline Cytarabine & $2 / 2$ & Meperidine & $1 / 1$ & Testosterone & \\
\hline Demecolcine $^{h}$ & $2 / 3$ & Mescaline & $1 / 2$ & enanthate ${ }^{b}$ & $0 / 1$ \\
\hline$n$-Demethyldiazepam & $1 / 1$ & Metaproterenol & $0 / 4$ & 2,3,7,8-Tetrachloro- & \\
\hline Desipramine $^{b}$ & $1 / 2$ & Methadone & $3 / 4$ & dibenzo- $p$-dioxin & $2 / 5$ \\
\hline
\end{tabular}


TABLE 3-Continued

\begin{tabular}{lccclr}
\hline Compound & Ratio $^{a}$ & Compound & Ratio $^{a}$ & Compound & Ratio $^{a}$ \\
\hline Theophylline & $1 / 2$ & Triamcinolone & $5 / 5$ & Valbanhan & $1 / 2$ \\
Thiocarlide & $0 / 1$ & Triamcinolone & & Vinblastine & $4 / 5$ \\
Thioguanine & $1 / 1$ & acetonide & $2 / 4$ & Vincristine & $5 / 5$ \\
Thioridizine & $1 / 3$ & Triethylenethio- & & Vitamin D & $2 / 2$ \\
Thiothixene & $0 / 3$ & phosphoramide & $2 / 2$ & Zarontin & $1 / 1$ \\
Thiouracil & $0 / 2$ & Trifluoperazine & $3 / 3$ & & \\
Thyrotropin & $1 / 2$ & Urethan & $3 / 3$ & & \\
\hline
\end{tabular}

${ }^{a}$ Ratio of the number of species found positive to the number of species tested.

${ }^{b}$ Although no positive human data are present these compounds are related to known or suspected human teratogens or are contraindicated during pregnancy by the manufacturers.

for which human teratologic effects have not been reported was observed $80 \%$ of the time for the monkey, $70 \%$ for the rabbit, but only $50 \%$ for the rat, $35 \%$ for the mouse, and $35 \%$ for the hamster.

Taken together, the correlations observed between human and animal teratogenic responses support the assumption that positive animal teratology studies are suggestive of a positive human response. However, the correlations, obtained using human and animal data for substances that appear "negative" in humans, suggest that limits probably exist on the predictive power of positive animal studies in any given test species. In addition, it must be emphasized that the degree of reliance that can be placed on these correlations to support the assumption that animal studies are relevant to humans is limited by the uncertainties that exist in the human data used to identify the 38 known or suspected human teratogens used in the comparisons (Schardein, 1976; Strobino et al., 1978; Yerushalmy, 1972; Council on Environmental Quality, 1981). Most of the 38 were identified only from a limited number of physician case reports. Very few have been the subject of rigorous, large-scale epidemiology studies, which provide the only basis for concluding unequivocally that a substance is a human teratogen. Similarly, the data available on the 165 substances for which teratologic effects have not been reported are not of sufficient quality and quantity to es- tablish conclusively that some 165 are not human teratogens.

As revealed by the data just cited, a factor that complicates the use of animal studies to predict potential teratogenic response in humans is the apparent variability in response to teratogenic agents among animal species (Brent, 1978; Schardein, 1976; Wilson, 1977a,b; Fraser, 1977). The reasons for the apparent variability and its relevance to the reliability of animal studies for predicting human response are not well understood (Nishimura and Shiota, 1977; Wilson, 1977b; Wilson and Fraser, 1977a; Schardein, 1976). It is important to realize, however, that the endpoint that is being measured (teratology) is not a single response. Unlike other toxicities, which have clear expressions (such as death, cancer, tumor, or organ damage), teratologic responses are numerous and varied and result from a continuous series of pathologic alterations during fetal development (Carter, 1973; Smith, 1976; Gorlin et al., 1976). Whether or not a particular chemical will induce a teratologic response in the fetus is dependent on a variety of factors and influences (listed above) that change from species to species. The mechanism of action in each species can also vary. Because of this inability of a positive response in a single species to predict the true teratogenic response in humans or other test species, regulatory agencies have routinely required multiple species to be tested (NAS, 1975, 1977; Health 
and Welfare Canada, 1975; USFDA, 1966, 1970; USEPA, 1978; OECD, 1979; WHO, 1967). This provides information on the most sensitive species from which to extrapolate margins of safety, and allows more confidence to be placed on the probable human response.

It is known that one major source of variability among species derives from the influence of the maternal organism on the way the fetus is affected by a chemical the mother ingests (Nishimura and Shiota, 1977; Beyer et al., 1970; Beck and Lloyd, 1977). The site of a chemical's teratogenic action can be primarily in the embryo or in the maternal organism and only secondarily in the embryo, or in both. Whatever the primary site of action is, however, the maternal organism always exerts some influence in determining the teratogenic or other embryotoxic effect of a substance with which it comes into contact, because it is through the mother that the substance is delivered to the fetus (Neubert et al., 1978; Beyer et al., 1970; Juchau, 1976). The route and rate of maternal absorption are the initial determinants of the concentration in the maternal bloodstream, but of equal or greater importance is what happens to a foreign chemical after it gets into the maternal blood. For example, it may be excreted by the kidney, metabolized by the liver, kidney, or other organs, bound to protein, stored in various tissues, or (and/or its metabolites) may simply remain in the blood plasma at varying concentrations for some period of time. The level of concentration in the blood and the lengths of time for which various levels are maintained are important in determining the total dosage that will be available for transfer by the placenta to the embryo or fetus (Gillette, 1977; Jusko, 1972; Bochert et al., 1978).

The agency (Flamm, 1983) has attached particular importance to research efforts in the comparisons of humans and experimental animals. Specific studies at the NCTR and Bureau of Foods have been directed toward understanding the fundamental processes of development and the mechanisms of malfor- mation; the development of a sound data base on comparative pharmacokinetics and metabolism to support better ways of extrapolating animal data to man; the development of improved and validated procedures for detecting the full range of possible injury which might occur during the life span of the organism; and, finally, the development of in vitro tests for detecting teratological events.

A number of studies in these four areas are currently underway in laboratories within the Agency, all involving multidisciplinary approaches to solving problems in developmental toxicology. For example, we are exploring studies on uterine and estrogen receptor development, on metabolic conversion and placental transport of the natural and synthetic estrogens, on the ontogeny of cardiovascular development and function, and the application of pharmacokinetics to the problem of predicting teratogenic effects from animal species to humans.

FDA also conducts in-house reviews of human and animal data through periodic meetings of its task force on maternal and child problems. In an effort to increase our data base on human birth defects that might be related to drug exposure, we have expanded the reproduction questionnaire included in our monitoring of case reports. These case reports are compared to epidemiological studies from the Boston University Drug Epidemiology Unit, the Boston University Drug Surveillance program, and programs at the University of California and Yale University. In addition, Michigan medicaid data involving about 32,000 deliveries yearly are also closely monitored. Collaboration with the Centers for Disease Control in Atlanta, Georgia, and the international Birth Defects Surveillance Center further extends our birth defect data bases as well. Specific reports of potentially significant human reproductive toxicity are passed to our task force on maternal and child health for evaluation. The assistance of outside experts and consultants is often solicited in deter- 
mining the significance of these reports (Flamm, 1983).

FDA realizes that laboratory studies alone will not lead to development of meaningful approaches to reproductive toxicity assessment unless experts agree on the scientific assumptions that support defensible extrapolation of animal and human developmental toxicity data. For this reason FDA has been active in developing criteria to support consistent interpretation and use of teratologic and reproductive data by Agency scientists, FDA took the lead role in the Interagency Regulatory Liaison Group sponsored workshop on reproductive toxicity risk assessment (Frankos, 1980). I personally chaired this work group and we strove to challenge the experts to examine critically the scientific assumptions that form the underpinnings of data evaluation and extrapolation. This activity involved 80 to 90 participants from universities, industry, and government. Six major topics were discussed and they included reproductive endpoints, teratology endpoints, pharmacokinetics, reproductive mechanisms, teratology mechanisms, and risk assessment statistics (Frankos, 1983). The results of the workshop will be published as a scientific report and made available to participants of the workshop and others in the scientific community.

A workshop sponsored by FDA/IRLG/ EPA met to evaluate the applicability of in vitro test systems as screens for potential teratogens. This was to encourage those interested in developing these systems to establish a well-controlled approach to validation and assist those interested in the application of such systems to use them in the overall risk assessment process. The proceedings of this workshop were published in the Journal of Teratogenesis, Carcinogenesis and Mutagenesis (Kimmel et al., 1982).

Because of the uncertainties presented above, the FDA has approached developmental toxicity assessment with deliberate caution. Rather than utilizing quantitative or estimates of risk, the FDA has adopted cat- egories of pregnancy risk for drugs and applies safety factors for food additives, color additives, and human food animal drugs. Drugs, radiation, medical devices, and biologics have the latitude of benefit/risk considerations which allow greater control over who, when, where, and how a woman of childbearing age will be exposed to these products. Unfortunately, food additives, color additives, cosmetics, and food animal drugs do not have this leeway and must assume that women of childbearing age will be exposed preconception, in utero, and postnatally. Clearly how risk from each product will be evaluated and what an acceptable risk will be for reproductive hazards will not be the same from product to product or use to use.

After several years of deliberation, the FDA instituted the 1979 uniform labeling regulations for drugs. These require that specific pregnancy information be present in the package insert labeling of all drugs (CFR 21: 201.57). These labels, usually located in the precaution section, were designed to provide the physician with enough animal and human developmental toxicity data to make a benefit/risk decision for his/her patient. The level of potential risk was established through the use of a matrix of human and animal reproductive toxicity data. Table 4 shows the matrix of possible outcomes for animal and human studies.

The five levels of potential risks are designated $(\mathrm{A}, \mathrm{B}, \mathrm{C}, \mathrm{D}, \mathrm{X})$ and must carry the types of labels shown in Appendix I. Category A applies to compounds that show no evi-

TABLE 4

Pregnancy Category Matrix

Animal teratology studiesoutcome

\begin{tabular}{cccc}
$\begin{array}{c}\text { Human studies } \\
\text { outcome }\end{array}$ & + & - & Not available \\
\cline { 2 - 4 }+ & X or D & X or D & X or D \\
- & B & A & A or B \\
Not available & C & B & C \\
\hline
\end{tabular}


dence of human developmental toxicity in well-controlled studies and have negative animal teratology studies. Category B applies to compounds that show no evidence of human developmental toxicity in well-controlled studies but have positive animal teratology studies. Compounds that have negative animal teratology studies but do not have adequate well-controlled human studies are also Category B. Category $\mathrm{C}$ is assigned to drugs with positive or inadequate animal teratology studies and are lacking well-controlled human studies. These drugs must bear a warning that indicates that their use in pregnancy should be avoided unless benefits clearly outweigh potential risks to the fetus. Drugs in which well-controlled human studies have demonstrated birth defects are assigned either Category D or X. Category D would include those drugs whose potential risks are acceptable in comparison to the benefits to the woman. Category $\mathrm{X}$ is assigned to those drugs whose potential risk to the fetus does not outweigh the benefits to the woman.

In the case of food additives, color additives, and human animal drugs, internal guidelines for utilization of developmental toxicity data for human risk assessment were recommended by the Teratology Guidelines Committee of the Bureau of Foods (unpublished) which was chaired by Dr. Benjamin Jackson. They emphasized that since women of childbearing age will be exposed to food additives continuously through all stages of fetal development, all endpoints of abnormal intrauterine development including death, malformations, growth deficits, and functional deficits must be considered. Collectively, these are referred to as "developmental" toxicity rather than emphasizing teratogenicity. An attempt was made to classify effects according to severity and reversibility. Two types of changes were identified. Type I changes are perceived as permanent (irreversible), possibly life-threatening, and frequently associated with gross malformations. Type II changes are perceived as nonperma- nent (reversible), are non-life threatening, and are not necessarily associated with induced malformations. Table 5 lists the specific endpoints that would be associated with Type I and II outcomes.

Present Bureau of Foods testing guidelines recommend a two-generation reproductive study, including a teratology phase, be performed for food additives and color additives. If the outcome of this study is either a Type I or II effect, then teratology testing in another species is required. Any combination of Type I effects in either the two-generation reproduction test or the teratology test would represent a Type I hazard. If Type II effects were produced in the initial test and either Type II or no effects were produced in the teratology test, then the substance would be handled on the basis of Type II effects. If no effects were produced in the two-generation study but additional testing was required due to potentially high exposure or suspect chemical structure, then the result of that would determine the type of hazard.

As for drugs, a matrix of outcomes was established (Table 6). Safety factors are applied to the no effect levels from the most sensitive species and endpoint to establish the acceptable exposures for humans. Variable safety factors are applied to the various

TABLE 5

DEVELOPMENTAL TOXICITY ENDPOINTS

\begin{tabular}{lc}
\hline & Type I \\
\hline $\begin{array}{l}\text { No. of live births } \\
\text { (litter size) }\end{array}$ & $\begin{array}{c}\downarrow \text { No. of live fetuses } \\
\text { (litter size) } \\
\uparrow \text { No. of resorptions } \\
\uparrow \text { No. of fetuses with } \\
\text { malformations, } \\
\text { structural changes }\end{array}$ \\
\hline No. of still births & Type I/Type II \\
\hline Birth weights & $\begin{array}{l}\text { Postnatal survival } \\
\downarrow \text { Postnatal growth, } \\
\text { reproductive capacity }\end{array}$ \\
& $\begin{array}{l}\text { No. of fetuses with } \\
\text { (skeletal, soft tissue) }\end{array}$ \\
\hline
\end{tabular}


TABLE 6

SAFETY FACTORS APPLIED TO OUTCOMES OF DEVELOPMENTAL TOXICITY TESTS

\begin{tabular}{|c|c|c|c|}
\hline \multirow{2}{*}{$\begin{array}{c}\text { Teratology } \\
\text { test }\end{array}$} & \multicolumn{3}{|c|}{ Findings from multigeneration test } \\
\hline & Type I & Type II & No effect \\
\hline \multirow[t]{2}{*}{ Type I } & Type I & Type I & Type I \\
\hline & $(1000 x)$ & & ()$^{a}$ \\
\hline \multirow[t]{2}{*}{ Type II } & Type I & Type II & Type II \\
\hline & $(\quad)^{a}$ & $(100 x)$ & $(100 \times)$ \\
\hline \multirow[t]{2}{*}{ No effect } & Type I & Type II & No effect \\
\hline & $(\quad)^{a}$ & $(100 x)$ & $(100 \times)$ \\
\hline
\end{tabular}

${ }^{a}$ An appropriate safety factor will be determined after consideration of additional information on metabolism, pharmacokinetics, natural toxicity, mechanism, etc.

outcomes depending on the category of the outcome in the matrix. As shown, a 1000fold safety factor would be applied in those cases where there is evidence of serious developmental effects in two species. On the other hand, a 100-fold safety factor would be applied to the no effect level for a Type II effect or to the highest dosage tested when there were no effects. When results in the two tests are discordant, consideration could be given to information on maternal toxicity, metabolic differences, and mechanism in selecting appropriate safety factors.

In conclusion, it is reasonable to assume that positive animal teratology studies are suggestive of potential human response. Wellconducted animal studies that show teratogenic effects at levels of exposure not substantially greater than humans might experience are sufficient to raise substantial questions about the potential risk to humans. However, at this time, no single test species can be said to predict accurately the true human response to a given chemical. Tests in multiple species may increase the predictive reliability of animal test data, but specific differences between the test species and the human system must be considered in evaluating the relevance of particular tests to humans. The FDA has approached developmental toxicity risk assessment with deliberate caution. Increased basic research coupled with better monitoring of human populations will eventually lead to a better understanding of how animal data can best be used to predict human reproductive risks. At present the FDA uses a matrix approach for assessing potential human developmental toxicity that incorporates the strength of the qualitative evidence. The toxicity matrix applied to drugs provides the physician with a relative pregnancy category from which a benefit/risk decision can be made. Food additives, color additives, and human animal drugs utilize a matrix with which to assign an overall level of concern for potential developmental toxicities (Type I or II) and then apply appropriate safety factors (100- to 1000 -fold).

\section{APPENDIX}

\section{Pregnancy Category Labeling (CFR 21:201.57)}

Pregnancy Category $A$. Studies in pregnant women have not shown that (name of drug) increases the risk of fetal abnormalities if administered during the first (second, third, or all) trimester(s) of pregnancy. If this drug is used during pregnancy, the possibility of fetal harm appears remote. Because studies cannot rule out the possibility of harm, however, (name of drug) should be used during pregnancy only if clearly needed.

Pregnancy Category $B$. Reproduction studies have been performed in (kind(s) of animal(s)) at doses up to $x$ times the human dose and have revealed no evidence of impaired fertility or harm to the fetus due to (name of drug). There are, however, no adequate and wellcontrolled studies in pregnant women. Because animal reproduction studies are not always predictive of human response, this drug should be used during pregnancy only if clearly needed.

Pregnancy Category B. Reproduction studies in (kind(s) of animal(s)) have shown (describe findings) at $x$ times the human dose. Studies in pregnant women, however, have not shown that (name of drug) increases the risk of abnormalities when administered during the first (second, third, or all) trimester(s) of pregnancy. Despite the animal findings, it appears that the possibility of fetal harm is remote, if the drug is used during pregnancy. Nevertheless, because the studies in humans cannot rule out the possibility of harm, (name of drug) should be used during pregnancy only if clearly needed.

Pregnancy Category $C$. (Name of drug) has been shown to be teratogenic (or to have an embryocidal 
effect or other adverse effects) in (name(s) of species) when given in doses $x$ times the human dose. There are no adequate and well-controlled studies in pregnant women. (Name of drug) should be used during pregnancy only if the potential benefit justifies the potential risk to the fetus.

Pregnancy Category $C$. Animal reproduction studies have not been conducted with (name of drug). It is also not known whether (name of drug) can cause fetal harm when administered to a pregnant woman or can affect reproduction capacity. (Name of drug) should be given to a pregnant woman only if clearly needed.

Pregnancy Category D. See "Warnings" section. Under the Warnings section, the labeling states, "(name of drug) can cause fetal harm when administered to a pregnant woman. (Describe the human data and any pertinent animal data.) If this drug is used during pregnancy, or if the patient becomes pregnant while taking this drug, the patient should be apprised of the potential hazard to the fetus.

Pregnancy Category $X$. See "Contraindications" section. Under "Contraindications," the labeling shall state, "(name of drug) may (can) cause fetal harm when administered to a pregnant woman. (Describe the human data and any pertinent animal data.) (Name of drug) is contraindicated in women who are or may become pregnant. If this drug is used during pregnancy, or if the patient becomes pregnant while taking this drug, the patient should be apprised of the potential hazard to the fetus.

\section{REFERENCES}

BECK, F., AND LLOYD, J. (1977). Comparative placental transfer. In Handbook of Teratology, Vol. 3, Comparative, Maternal, and Epidemiological Aspects (J. G. Wilson and F. C. Fraser, eds.), Plenum, New York.

BEYER, W. A., AU, W. Y., LAND, W. A., et al. (1970). Studies on the detection of adverse drug reactions in the newborn. I. Fetal exposure to maternal medication. J. Amer. Med. Assoc. 213, 2046-2048.

BOCHERT, G., RAHM, U., AND SCHNIEDERS, B. (1978). Pharmacokinetics of embryotoxic direct-acting alkylating agents: comparison of DNA alkylation of various maternal tissues and the embryo during organogenesis. In Role of Pharmacokinetics in Prenatal and Perinatal Toxicology (D. Neubert, H.-J. Merker, H. Nau, and J. Langman, eds.), pp. 235-521. Georg Thieme, Stuttgart.

BRENT, R. L. (1978). Weak teratogens (letter). Teratology $17,183$.

CARTER, C. O. (1973). Multifactorial genetic disease. In Medical Genetics (R. Clairborne, ed.), H. P. Publishing, Nèw York.

ColuINS, T. F. X. (1978). Reproduction and teratology guidelines: Review of deliberations by the National
Toxicology Advisory Committee's Reproduction Panel. J. Environ. Pathol. Toxicol. 2, 141-147.

Council on Environmental Quality (1981). Chemical Hazards to Human Reproduction. Prepared by Clement Associates, Inc.

Federal Register (1980). Deletion of GRAS status, proposed declaration that no prior sanction exists, and use of an interim basis pending additional study. Fed. Regist. 45, 69817-69838.

Fitzhugh, O. G. (1959). Chronic oral toxicity. In Appraisal of the Safety of Chemicals in Foods, Drugs and Cosmetics. pp. 36-45. Association of Food and Drug Officials of the United States, Topeka, Kans.

Flamm, W. G. (1983). In Testimony in Hearing on Relationship of Exposure to Toxic Chemicals and Reproductive Impairment. Committee on Science and Technology, U.S. House of Representatives, July 27, 1982. U.S. Govt. Printing Office, Washington, D.C.

FRANKOS, V. H. (1980). Reproductive toxicity risk assessment task group: Outline of work plan and request for comments. Fed. Regist. 45, 63553-63554.

FRANKOS, V. H. (1983). In Testimony in Hearing on Relationship of Exposure to Toxic Chemicals and Reproductive Impairment. Committee on Science and Technology, U.S. House of Representatives, July 27, 1982. U.S. Govt. Printing Office, Washington, D.C.

Fraser, F. C. (1977). Relation of animal studies to the problem in man. In Handbook of Teratology, Vol. 1, General Principles and Etiology (J. G. Wilson and F. C. Fraser, eds.). Plenum, New York.

GILLETTE, J. R. (1977). Factors that affect drug concentrations in maternal plasma. In Handbook of Teratology, Vol. 3, Comparative, Maternal, and Epidemiologic Aspects (J. G. Wilson and F. C. Fraser, eds.), pp. 3578. Plenum, New York.

Gorlin, R. J., PindBorg, J. J., AND COHEN, M. M. (1976). Syndromes of the Head and Neck. 2nd ed. McGraw-Hill, New York.

Health and Welfare Canada (1975). The Testing of Chemicals for Carcingenicity, Mutagenicity and Teratogenicity. Published by authority the Honorable Mare Lalonde, Minister of Health and Welfare Canada. JuCHAU, M. R. (1976). Drug reactions in the placenta. In (B. L. Mirkin, ed.), Perinatal Pharmacology and Therapeutics Academic Press, New York.

JUSKo, W. (1972). Pharmacodynamic principles in chemical teratology: Dose effect relationships. J. Pharmacol. Exptl. Therap. 183, 469-480.

KFLSFY, F. O. (1974). Present guidelines for teratogenic studies in experimental animals. In Congenital Defects-New Guidelines in Research (D. T. Janerich, R. G. Skalko, and I. H. Porter, eds), pp. 195-204. New York: Academic Press, Inc., New York, NY.

Kimmel, G. L., SMITH, K., KochaR, D. M., aND PRATT, R. M. (1982). Overview of in vitro teratogenicity testing: aspects of validation and application to screening. Teratogenesis, Carcin. Mutagen. 2, 221-229. 
National Academy of Sciences (NAS). (1975). Principles for Evaluating Chemicals in the Environment. Washington, D.C., pp. 72.

National Academy of Sciences (NAS). (1977). Principles and Procedures for Evaluating the Toxicity of Household Substances. Washington, D.C., pp. 72.

Neubert, D., Merker, H.-J., NAU, H., AND LANGMAN, J. (eds.) (1978). Role of Pharmacokinetics in Prenatal and Perinatal Toxicology. Georg Thieme, Stuttgart.

NishimuRa, H., AND SHIOTA, K. (1977). Summary of comparative embryology and teratology. In Handbook of Teratology, Vol. 3, Comparative, Maternal, and Epidemiologic Aspects (J. G. Wilson and F. C. Fraser, eds.), Plenum, New York.

Organization for Economic Cooperation and Development (OECD) (1979). OECD Short Term and Long Term Toxicology Groups: Final report. December 31, 1979.

SChardein, J. L. (ed.) (1976). Drugs as Teratogens. CRC Press, Cleveland, Ohio.

SHEPARD, T. H. (1976). A Catalog of Teratogenic Agents, 2nd ed. Johns Hopkins Univ. Press, Baltimore.

SMITH, D. W. (1976). Recognizable Patterns of Human Malformation, 2nd ed. Saunders, Philadelphia.

Strobino, B. R., Kuine, J., and Steine, F. (1978). Chemical and physical exposure of parents: Effects on human reproduction and offspring. J. Early Hum. Dev. 1, 371-399.

U.S. Environmental Protection Agency (USEPA) (1978). Proposed guidelines for registering pesticides in the U.S.: Hazard evaluation: Humans and domestic animals. Fed. Regist. 43, 37335-37402.

U.S. Food and Drug Administration (USFDA) (1966). Guidelines for Reproduction Studies for Safety Evaluation of Drugs for Human Use.

U.S. Food and Drug Administration (USFDA) (1970). Advisory committee on protocols for safety evaluation:
Panel on reproduction report on reproduction studies in safety evaluation of food additives and pesticide residues. Toxicol. Appl. Pharmacol. 16, 264-296.

U.S. Food and Drug Administration (USFDA) (1980). Caffeine: Deletion of GRAS status, proposed declaration that no prior sanction exists, and use on an interim basis pending additional study; proposed regulation. Federal Register 45(205), 69817-69838.

U.S. Food and Drug Administration (USFDA) (1982). Toxicological principles for safety assessment of direct food additives and color additives used in foods: Notice of availability. Fed. Regist. 47 (October 15), 46, 141-142.

U.S. Pharmacopeiă (1980). Dispensing Information.

WILSON, J. G. (1973). Environmental and Birth Defects. Academic Press, New York.

WILSON, J. G. (1977a). Teratogenic effects of environmental chemicals. Fed. Proc. 36, 1698-1703.

WILSON, J. G. (1977b). Current status of teratologygeneral principles and mechanisms derived from animal studies. In Handbook of Teratology, Vol. 1, General Principles and Etiology. (J. G. Wilson and F. C. Fraser, eds.). Plenum, New York.

WILSON, J. G., AND Fraser, F. C. (eds.) (1977a). Handbook of Teratology, Vol. 1, General Principles and Etiology. Plenum, New York.

Wilson, J. G., and Fraser, F. C. (eds.) (1977b). Handbook of Teratology, Vol. 3, Comparative, Maternal, and Epidemiological Aspects. Plenum, New York.

World Health Organization (WHO) (1967). Principles for the Testing of Drugs for Teratogenicity. ITS Tech. Ser. No. 364.

YeRUSHALMY, J. (1972). Methodologic problems encountered in investigating the possible teratogenic effects of drugs. In Drugs and Fetal Development. (M. A. Klingberg, A. Abramovivi, and J. Chemke, eds.). Plenum, New York. 